\title{
Death-feigning and Defensive Behavior in Two Snakes of the Andaman and Nicobar Archipelago of India
}

\author{
S.R. Chandramouli
}

Department of Ecology and Environmental Sciences, School of Life Sciences, Pondicherry University, Puducherry-605014, India (findthesnakeman@gmail.com)

$\mathrm{D}$ efensive behaviors used by animals to avoid predation include flight, crypsis, and death-feigning (thanatosis), with the latter known to occur in some species of fishes (e.g., Mckaye 1981; Howe 1991), birds (e.g., Sargent and Eberhardt 1975), mammals (e.g., Francq 1969), and many reptiles (summarised in Patel et al. 2016 and Deshmukh et al. 2020). Herein I describe two instances in two species of snakes from the Andaman and Nicobar Islands.

Although Vijayakumar and David (2006) recorded new records of the Nicobar Kukri Snake (Oligodon woodmasoni) from islands in the Nicobar Archipelago, little is known about the behavior and natural history of this species. During herpetological surveys on Camorta, which is in the central group of the Nicobar Archipelago, I observed an adult female mov-

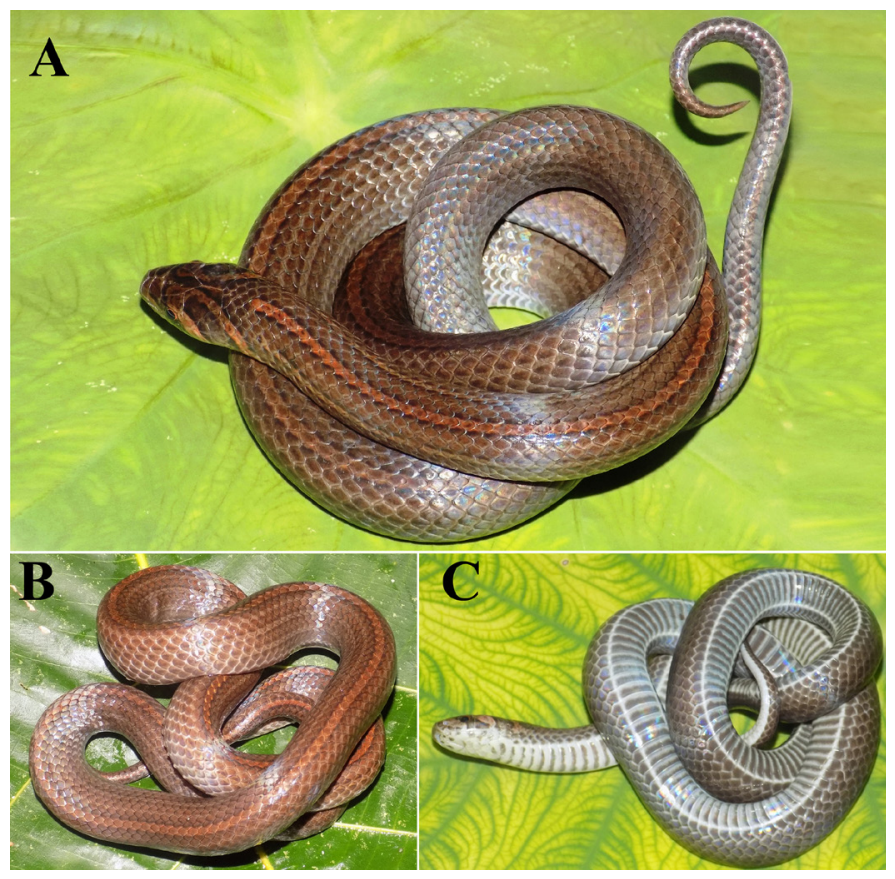

Fig. 1. Defensive behaviors of a Nicobar Kukri Snake (Oligodon woodmasoni): tail-curling (A), head-hiding (B), and death-feigning (C). Photographs by S.R. Chandramouli. ing actively at about $2100 \mathrm{~h}$ on the trunk of a tree at a height of about $2 \mathrm{~m}$ above the ground at Changua $\left(08.0157^{\circ} \mathrm{N}\right.$, $93.4995^{\circ} \mathrm{E} ; 188.4 \mathrm{~m}$ asl). While being photographed (Fig. 1 ), the snake coiled its body tightly and hid its head within the coils, remaining motionless for about $2 \mathrm{~min}$. It subsequently curled its tail above its body, presumably in an effort to distract a putative predator. Such tail-curling behavior has been reported by David et al. (2012) and Seshadri (2014) in several congeners (O. albocinctus, O. cyclurus, O. nago, and O. octolineatus). The snake then twisted its body coils, exposing its venter, and feigned death. This the first report of such behavior by Oligodon woodmasoni and is also the first record of the species from Camorta.

When approached, an adult female Tytler's Keelback (Fowlea tytleri) (SVL $-1,000 \mathrm{~mm}$ ) that had been rescued from the hostel in Port Blair, South Andaman $\left(11.6339^{\circ} \mathrm{N}\right.$, $92.7424^{\circ} \mathrm{E} ; 75 \mathrm{~m}$ asl) inverted its body, exposed its venter, and feigned death (Fig. 2). After being left undisturbed for one minute, it slowly raised its head, presumably checking if the threat had passed, before assuming a natural position. Vogel and Han-Yuen (2010) described death-feigning behavior in a congener, the Checkered Keelback (Fowlea piscator).

\section{Literature Cited}

David, P., T.Q., Nguyen, T.T. Nguyen, K. Jiang, T. Chen, A. Teynié, and T. Ziegler. 2012. A new species of the genus Oligodon Fitzinger, 1826 (Squamata: Colubridae) from northern Vietnam, southern China and central Laos. Zootaxa, 3498: 45-62.

Deshmukh, R.V., S.A. Deshmukh, S.A. Badhekar, U.M. Udapure, and S.K. Hattimare. 2020. Death-feigning behavior in the Common Sand Boa, Eryx conicus (Schneider 1801) (Erycidae), and the Common Wolfsnake, Lycodon aulicus (Linnaeus 1758) (Colubridae). Reptiles \& Amphibians 27: 65-67.

Francq, E.N. 1969. Behavioral aspects of feigned death in the opossum Didelphis marsupialis. American Midland Naturalist 81: 556-558.

Howe, J.C. 1991. Field observations of death feigning in the Convict Tang, Acanthurus triostegus (Linnaeus), with comments on the nocturnal color pattern in juvenile specimens. Journal of Aquariculture \& Aquatic Sciences 6: $13-15$.

McKaye, K.R. 1981. Field observation on death feigning: a unique hunting behavior by the predatory cichlid, Haplochromis livingstoni, of Lake Malawi. Environmental Biology of Fishes 6: 361-365. 


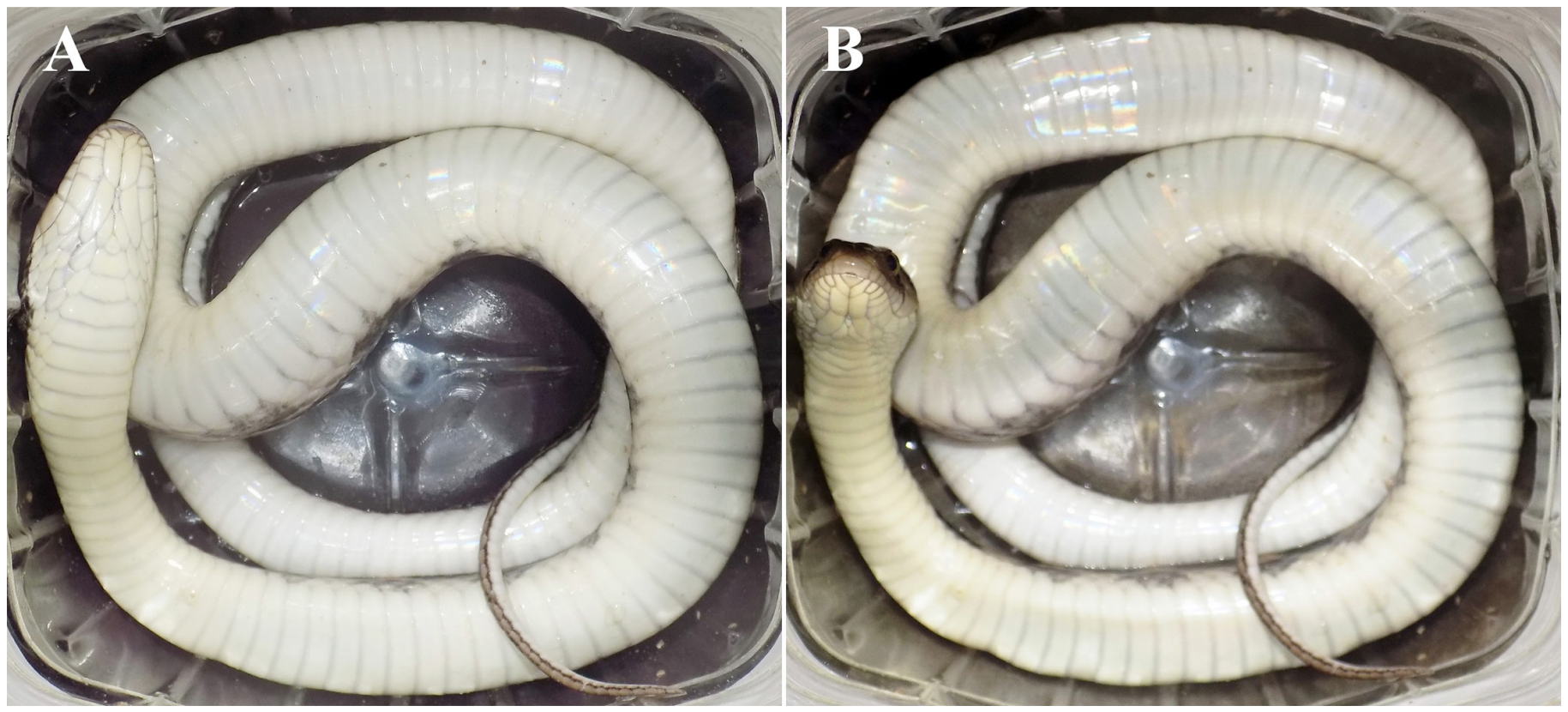

Fig. 2. Death-feigning behavior in Tytler's Keelback (Fowlea tytleri) (A) and checking for threats after a period of one minute (B). Photographs by S.R. Chandramouli.

Patel, H., V. Naik and S.K. Tank. 2016. Death-feigning behavior in two species of Lygosoma (Squamata, Scincidae) from India. Phyllomedusa 15: 191-194.

Sargeant, A.B. and L.E. Eberhardt. 1975. Death feigning by ducks in response to predation by Red Foxes (Vulpes fulva). American Midland Naturalist 94: 108-119.

Seshadri, K.S. 2014. Display behaviour in response to a perceived threat by Indian short-headed kukri snake Oligodon brevicaudus (Günther, 1862) (Squamata:
Colubridae). Herpetology Notes 7: 447-450.

Vijayakumar, S.P. and P. David. 2006. Taxonomy, natural history, and distribution of the snakes of the Nicobar Islands (India), based on new materials and with an emphasis on endemic species. Russian Journal of Herpetology 13: 11-40.

Vogel, G. and H.K. Han-Yuen. 2010. Death feigning behavior in three colubrid species of tropical Asia. Russian Journal of Herpetology 17: 15-21. 